\title{
Nebulised sodium cromoglycate in the preschool wheezy child
}

\author{
W. LENNEY AND A. D. MILNER \\ From the Department of Child Health, University Hospital and Medical School, Nottingham
}

SUMMARY A double-blind controlled study of 14 preschool children with recurrent wheezing episodes was performed to show the effectiveness of nebulised sodium cromoglycate in inhibiting exercise-induced bronchoconstriction in this young age group. All 14 children showed markedly less exercise-induced bronchoconstriction after nebulised sodium cromoglycate, 13 of them to a degree indistinguishable from results obtained in normal healthy children in the same age group. Nebulised water afforded protection from exercise-induced bronchoconstriction in some children. This study gives further evidence that sodium cromoglycate is an effective therapeutic agent in children under the age of 5 years.

In a recent study (see accompanying article, p. 468) we found that children from 3 to 5 years of age with recurrent wheezing episodes show exercise-induced bronchoconstriction in a similar manner to older asthmatic children (Jones et al., 1962; Godfrey, 1974). A further long-term study indicated that nebulised sodium cromoglycate was effective in reducing asthmatic symptoms, particularly coughing, in this age group (Hiller et al., 1978). It is known that in older children with asthma, sodium cromoglycate is effective in inhibiting exercise-induced bronchoconstriction (Godfrey, 1974; Connolly and Godfrey, 1970). The aim of this study was to determine if nebulised sodium cromoglycate inhibits exercise-induced bronchoconstriction in the preschool wheezy child.

\section{Subjects}

Fourteen children ( 8 boys, 6 girls) took part in the study. All were attending paediatric outpatient clinics in Nottingham with a history of recurrent wheezing episodes. Their ages ranged from 3 years 2 months to 5 years 1 month (mean 4 years). 8 of the children had eczema and 11 had a family history of asthma. 13 had received bronchodilator therapy previously and 6 were taking sodium cromoglycate by Spinhaler. All therapy was stopped for at least 12 hours before each investigation. Each child was examined immediately before the run. On no occasion did any of the children have clinical evidence of airways obstruction on arrival at the laboratory.

Received 8 November 1977

\section{Method}

Apparatus. Two systems were used to assess lung function. (i) Wright's low range peak flow meter. This has been shown to provide reproducible results down to the age of $2 \frac{1}{2}$ years (Milner and Ingram, 1970). (ii) A modification of the forced oscillation technique. The technique is based on the principle that when a sine-wave flow oscillation is applied to the respiratory system at the resonant frequency, the impedance to the oscillatory flow is due solely to the total respiratory resistance $\left(R_{\mathrm{T}}\right)$, since at resonance the elastic and inertial impedance are of equal magnitude and opposite in sign. The apparatus is described in detail in the previous article (Lenney and Milner, 1978).

Procedure. Each child attended the laboratory on three occasions. On the first visit to the laboratory peak expiratory flow rate (PEFR) was measured using the Wright's low range peak flow meter and the best of three consecutive flows was recorded. $\mathbf{R}_{\mathrm{T}}$ was measured with the child seated. The hands of one of the investigators held the child's nose and stabilised the cheeks. At least three consecutive respiratory cycles were recorded. PEFR and $R_{T}$ measurements were repeated 20 minutes later and again at 2, 5, 10, 20, and 25 minutes after the child had run along an indoor corridor for 6 minutes. As these children were very young, it was necessary for one of us (W.L.) to accompany them on the run. On each occasion the child's heart rate exceeded 170 per minute at the end of the run. 
Thirty minutes after the run each child inhaled $1 \mathrm{ml} 0.5 \%$ salbutamol respirator solution diluted in $1 \mathrm{ml}$ sterile water from the face mask of a commercial nebuliser (Pari). Measurements of $R_{T}$ and PEFR were repeated 2 and 5 minutes after nebulisation was completed.

On two subsequent visits the procedure was identical except that 5 minutes before the run each child received $20 \mathrm{mg}$ sodium cromoglycate dissolved in $2 \mathrm{ml}$ sterile water, or $2 \mathrm{ml}$ sterile water, through the face mask of the Pari nebuliser. These solutions were previously coded by Fisons Laboratories and the code was not broken until the end of the study so that all solutions were given under double-blind conditions. Each child performed the three exercise tests within 2 weeks. To check the reproducibility of the exercise tests 5 children attended the laboratory on a fourth occasion. No medication was given before exercise in these repeat studies.

\section{Results (Table)}

After the initial run the mean peak percentage fall in PEFR was $44 \cdot 5 \%$ (range 15.5-68) and the mean peak percentage rise in $R_{\mathrm{r}}$ was $73.9 \%$ (range 38142). After inhalation of sodium cromoglycate solution the group mean PEFR was in fact $3 \%$ above the base-line reading (range -30 to +19 ) and the mean peak percentage rise in $R_{T}$ was $2.3 \%$ (range -15 to +16 ). After inhalation of water the mean peak percentage fall in PEFR after exercise was $16 \%$ (range -5 to +55 ) and the mean peak percentage rise in $R_{T}$ was $32.8 \%$ (range 24 to 75 ) (Fig.). Individually, 13 of the 14 children after inhalation of sodium cromoglycate had maximal percentage postexercise PEFR and $R_{T}$ changes which were indistinguishable from those of normal healthy children of the same age (Lenney and Milner, 1978). After inhalation of water, maximal percentage postexercise PEFR changes were within the normal range in 6 children and maximal percentage postexercise $R_{T}$ changes were within the normal range in 3. After inhalation of salbutamol the mean peak
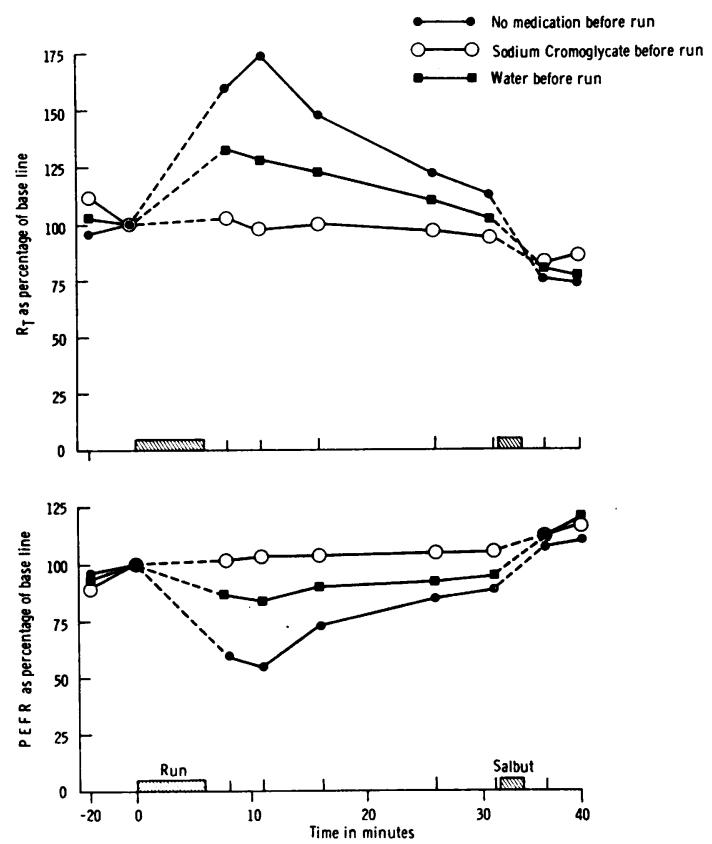

Fig. Mean total respiratory resistance $\left(R_{T}\right)$ and mean peak expiratory flow rate (PEFR) before and after three 6-minute runs and after inhalation of nebulised salbutamol in 14 children with recurrent wheezing. The results are expressed as a percentage of the readings obtained immediately before the run.

Table Peak expiratory flow rate (PEFR) and total respiratory resistance $\left(R_{T}\right)$ before and after exercise, and after salbutamol in 14 children. On the first occasion no therapy was given in the 20 minutes between the initial and base-line reading (no inhalation). On the two subsequent visits the child was given either water (water inhalation) or sodium cromoglycate solution (SCG inhalation). The results are expressed as a percentage of the base-line reading. Mean values for the group are given $\pm 1 S D$ in parentheses.

\begin{tabular}{|c|c|c|c|c|c|c|}
\hline & \multicolumn{2}{|l|}{ No inhalation } & \multicolumn{2}{|c|}{ Water inhalation } & \multicolumn{2}{|c|}{ SCG inhalation } \\
\hline & PEFR & $\boldsymbol{R}_{T}$ & PEFR & $\boldsymbol{R}_{\boldsymbol{T}}$ & PEFR & $\boldsymbol{R}_{T}$ \\
\hline Initial & $\begin{array}{r}96 \cdot 5 \quad(8 \cdot 6) \\
100 \cdot 0\end{array}$ & $\begin{array}{r}96 \cdot 5 \quad(6 \cdot 7) \\
100 \cdot 0\end{array}$ & $\begin{array}{l}94 \cdot 3(13 \cdot 2) \\
100 \cdot 0\end{array}$ & $\begin{array}{l}102 \cdot 3(9 \cdot 0) \\
100 \cdot 0\end{array}$ & $\begin{array}{l}89.9(16.0) \\
100.0 \approx\end{array}$ & $\begin{array}{l}112 \cdot 7(12 \cdot 8) \\
100 \cdot 0\end{array}$ \\
\hline $\begin{array}{l}+2 \mathrm{~min} \\
+5 \mathrm{~min} \\
+10 \mathrm{~min} \\
+20 \mathrm{~min} \\
+25 \mathrm{~min}\end{array}$ & $\begin{array}{l}60.5(20.0) \\
56 \cdot 5(18 \cdot 0) \\
74.0(18 \cdot 5) \\
86 \cdot 7(14 \cdot 1) \\
88 \cdot 7(11 \cdot 2)\end{array}$ & $\begin{array}{l}160.4(32 \cdot 0) \\
173.9(36 \cdot 1) \\
147 \cdot 2(25 \cdot 8) \\
122 \cdot 7(21 \cdot 7) \\
115 \cdot 3(26 \cdot 9)\end{array}$ & $\begin{array}{l}87.6(23 \cdot 5) \\
84.0(23 \cdot 0) \\
90.1(11 \cdot 4) \\
92.8(14 \cdot 8) \\
94.4(12 \cdot 7)\end{array}$ & $\begin{array}{l}132.8(29.2) \\
127 \cdot 3(28 \cdot 2) \\
122.0(19 \cdot 8) \\
110 \cdot 2(19 \cdot 9) \\
102 \cdot 2(20 \cdot 4)\end{array}$ & $\begin{array}{lr}101 \cdot 9 & (8 \cdot 2) \\
103 \cdot 6 & (13 \cdot 2) \\
103 \cdot 8 & (5 \cdot 9) \\
105 \cdot 2 & (6 \cdot 4) \\
105 \cdot 7 & (7 \cdot 6)\end{array}$ & $\begin{array}{rr}102.3 & (8 \cdot 7) \\
98 \cdot 4 & (6 \cdot 9) \\
100 \cdot 0 & (5 \cdot 9) \\
98 \cdot 6 & (7 \cdot 3) \\
95 \cdot 0 & (5 \cdot 8)\end{array}$ \\
\hline $\begin{array}{l}\text { After salbutamol } \\
+2 \mathrm{~min} \\
+5 \mathrm{~min}\end{array}$ & $\begin{array}{l}108 \cdot 5(12 \cdot 6) \\
111.6(13 \cdot 3)\end{array}$ & $\begin{array}{l}75.8(19.0) \\
74.5(17.9)\end{array}$ & $\begin{array}{l}112.0(14.0) \\
118.0(16.0)\end{array}$ & $\begin{array}{l}81 \cdot 1(15 \cdot 7) \\
76 \cdot 7(9 \cdot 9)\end{array}$ & $\begin{array}{l}112 \cdot 8(18 \cdot 7) \\
116 \cdot 5(19 \cdot 1)\end{array}$ & $\begin{array}{l}83 \cdot 2(13 \cdot 8) \\
86.4(12 \cdot 7)\end{array}$ \\
\hline
\end{tabular}


percentage rise in PEFR was $22.9 \%$ on the initial visit, $21.9 \%$ when water had been given before the run, and $10.8 \%$ when sodium cromoglycate had been given before the run. The mean peak percentage fall in $R_{\mathrm{T}}$ after salbutamol inhalation was $\mathbf{4 0 . 8 \%}$ on the initial visit, $25.5 \%$ when water had been given before the run, and $3 \cdot 2 \%$ when sodium cromoglycate had been given before the run.

The 5 children in whom repeat exercise tests were carried out showed a mean percentage fall in PEFR of $41 \%$ (range $30-53$ ) and a mean percentage rise in $R_{T}$ of $74 \%$ (range 33-120).

\section{Discussion}

Clinically the most important finding in this study is that nebulised sodium cromoglycate given 5 minutes before the run reduced the degree of exercise-induced bronchoconstriction in all 14 children and in 13 of those tested to a degree indistinguishable from normal healthy children in the same age group (Lenney and Milner, 1978). Previous studies in older asthmatic children have also shown the effectiveness of sodium cromoglycate in blocking exercise-induced bronchoconstriction, but the effect has often been partial or only present in approximately $75 \%$ of the children studied (Blackhall and Jones, 1970; Connolly and Godfrey, 1970; Shapiro et al., 1975). We are unable to say whether this represents a better response to sodium cromoglycate in the younger age group or whether factors such as the method of administration of the drug affect the response. The high placebo response in this study is in keeping with previous work in older children (Godfrey and Silverman, 1973), which showed significant reduction in exerciseinduced bronchoconstriction after administration of placebo in $41 \%$ of asthmatic children.

In the 5 children who performed a repeat control exercise test some weeks later, the mean percentage rise and fall of $R_{T}$ and PEFR was very similar to the initial control test. We therefore consider that the prevention of exercise-induced bronchoconstriction both by sodium cromoglycate and water was a true clinical response and did not represent an increased tolerance to exercise. The exercise studies were unsophisticated and relatively nonstandardised as in this age group detailed measurements of work done are most unlikely to be successful. However, we did consider that a heart rate of over 170 beats per minute did indicate the children had undertake an prolonged severe exercise.

\section{Conclusions}

(1) Sodium cromoglycate is an effective drug in preventing exercise-induced bronchospasm in children between the ages of 3 and 5 years with recurrent wheezing episodes. (2) Inhalation of sodium cromoglycate via the face mask of a nebuliser is an acceptable and effective way of administering the drug. (3) When evaluating the effectiveness of a drug in preventing exercise-induced bronchoconstriction, the high placebo response necessitates that the studies be carried out under double-blind controlled conditions even at this young age.

We gratefully acknowledge financial support from the Chest and Heart Foundation and from Fisons Laboratories.

\section{References}

Blackhall, M. I., and Jones, R. S. (1970). Effect of intal on post-exercise bronchoconstriction in asthma. Disodium Cromoglycate in Allergic Airways Disease. Ed. by J. Pepys and $\mathbf{H}$. W. Frankland. Butterworth, London.

Connolly, N. M., and Godfrey, S. (1970). Assessment of the child with asthma. Journal of Asthma Research, 8, 31-36.

Godfrey, S. (1974). Exercise Testing in Children, Chap. 5. Saunders, London.

Godfrey, S., and Silverman, M. (1973). Demonstration of placebo responses in asthma by means of exercise testing. Journal of Psychosomatic Research, 17, 293-297.

Hiller, E. J., Milner, A. D. and Lenney, W., (1977). Nebulized sodium cromoglycate in young asthmatic children: double-blind trial. Archives of Disease in Childhood, 53, 875-876.

Jones, R. S., Buston, M. H., and Wharton, M. J. (1962). The effect of exercise on ventilatory function in the child with asthma. British Journal of Diseases of the Chest, 56, 78-86.

Lenney, W., and Milner, A. D. (1978). Recurrent wheezing in the preschool child. Archives of Disease in Childhood, 53, 468-473.

Milner, A. D., and Ingram, D. (1970). Peak expiratory flow rates in children under five years of age. Archives of Disease in Childhood, 45, 780-782.

Shapiro, G. G., Plerson, W. E., and Bierman, C. W. (1975). The effect of cromolyn sodium on exercise-induced bronchospasm using a free running system. Pediatrics, 56, Suppl., 923-926.

Correspondence to Dr A. D. Milner, Department of Child Health, University Hospital and Medical School, Clifton Boulevard, Nottingham NG7 2UH. 